\title{
The Relationship Between Students' E-Health Literacy and General Health in a Military University of Medical Sciences
}

\author{
Isazadeh. $\mathrm{M}^{1}$ \\ ${ }^{*}$ Asadi. ZS 2 \\ Jamshidian. $A^{3}$ \\ Khademi Geshlaghe. $\mathrm{R}^{4}$ \\ 1- Student of Medicine, Student \\ Research Committee, Faculty \\ of Medicine, Aja University \\ of Medical Sciences, Tehran, \\ Iran. \\ 2- ( ${ }^{*}$ Corresponding Author) \\ Ph.D. in Health Education \\ and Promotion, Assistant \\ Professor, Community \\ Medicine, Department Faculty \\ of Medicine, Aja University of \\ Medical Sciences, Tehran, Iran \\ Email: 2006.asadi@gmail.com \\ 3- BSc in Student of Nursing, \\ Student Research Committee, \\ Faculty of Nursing, Aja \\ University of Medical Sciences, \\ Tehran, Iran. \\ 4- BSc in Student of Operating \\ Room, Student Research \\ Committee, Faculty of \\ Paramedicine, Aja University \\ of Medical Sciences, Tehran, \\ Iran
}

\begin{abstract}
Introduction: Electronic health literacy is a combination of skills in terms of health, information, science, computer, and internet. Improving students' scientific and practical abilities and promoting their academic achievement require good general health.
\end{abstract}

Objective: The present study aimed at assessing the relationship between e-health literacy and general health of students of Aja University of Medical Sciences in 2018.

Material and Methods: The present cross sectional, descriptive-analytical study was conducted on 305 students of Aja University of Medical Sciences in 2018 enrolled with convenience sampling. Data collection tools included demographic questionnaire, e-health literacy scale (e-Heals), and general health questionnaire (GHQ-28). The relationship between variables was assessed using Spearman correlation test, and groups were compared using the Mann-Whitney $U$ and the Kruskal-Wallis tests. Data were analyzed using SPSS version 23 and $\mathrm{P}<0.05$ was considered significant.

Results: A total of 305 questionnaires were analyzed. Students' mean score of e-health literacy was $28.15 \pm 5.9$, and that of general health was $27.24 \pm 16.67$. According to GHQ-28, a lower score indicates better general health; a significant and inverse correlation was observed between students' e-health literacy and general health $(\mathrm{r}=-0.139, \mathrm{P}=0.015)$. E-health literacy had no significant relationship with the subscales of physical status, anxiety, insomnia, and social dysfunction, but it had a significant and inverse relationship with the subscale of depression $(r=-0.198$, $\mathrm{P}=0.001)$.

Discussion and Conclusion: Better general health was associated with higher e-health literacy. This relationship affects general health improvement and it seems that taking measures to promote e-health literacy improves general health in students. Further studies are recommended to examine how these factors affect one another.

Keywords: E-Health Literacy, General Health, Students. 


\section{بررسى ارتباط بين سواد سلامت الكترونيك و سلامت عمومى دانشجويان يك دانشعاه علوم يزشكى نظامى سنى}

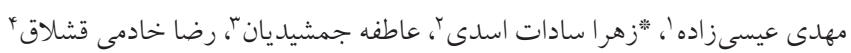

جكيده

مقدمه: كسب سواد سلامت الكترونيك نيازمند تركيبى از مهارتهاى بهداشتى، اطلاعاتى، دانشى، رايانه و سواد استفاده

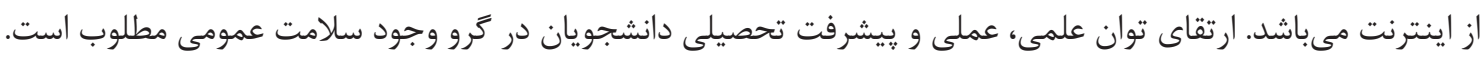

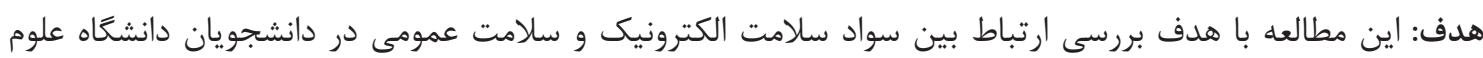
يزشكى آجا در سال لو با انجام شد.

مواد و روشها: مطالعه حاضر يك بررسى مقطعى (توصيفى - تحليلى) بر روى هـr نفر از دانشجويان دانشكاه علوم

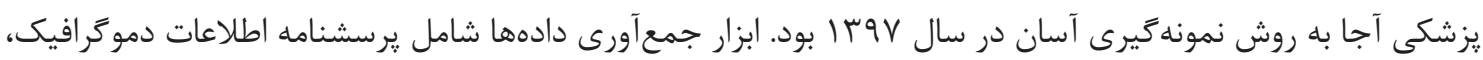

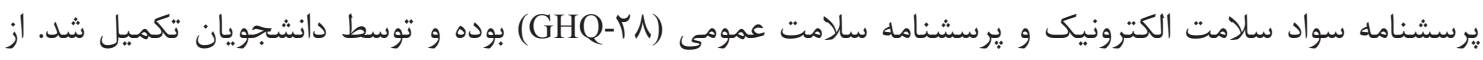

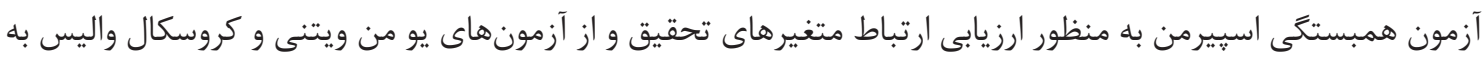

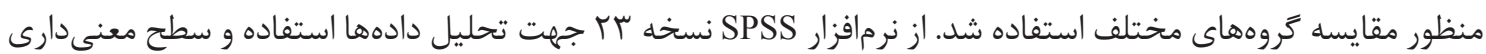

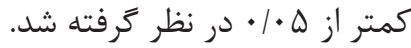

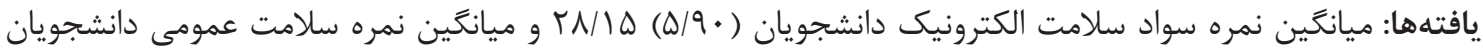

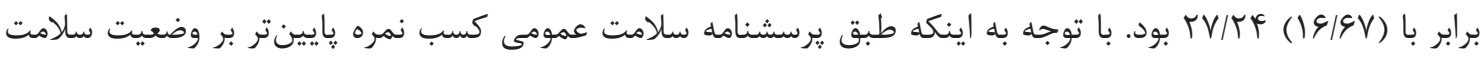

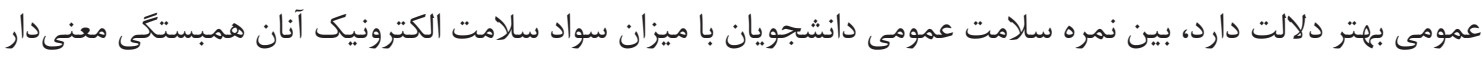

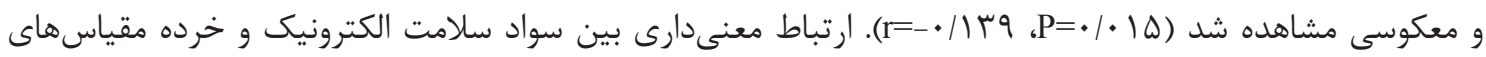
وضعيت جسمانى، اضطراب و بىخوابى و عملكرد اجتماعى مشاهده نشد اما سواد سلامت الكترونيك دانشجويان با خرده

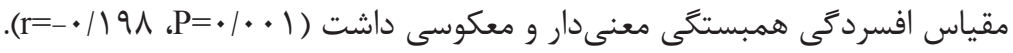

بحث و نتيجهَيرى: سلامت عمومى بهتر با سواد سلامت الكترونيك بالاتر همراه بود. دانستن اين ارتباط در بهبود وضعيت

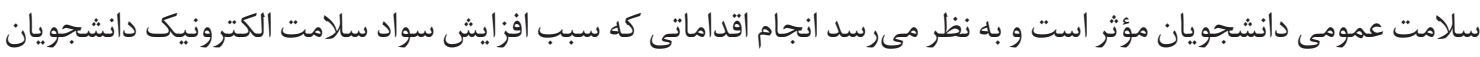

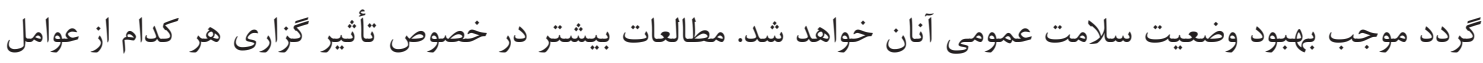

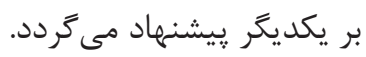

كلمات كليدى: سواد سلامت الكترونيك، سلامت عمومى، دانشجويان.

\begin{tabular}{|c|c|c|}
\hline I & 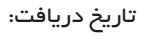 & 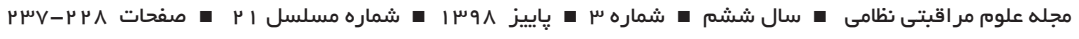 \\
\hline १ & 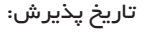 & \\
\hline १^/१/ル。 & 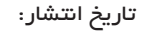 & \\
\hline
\end{tabular}

تا به منظور ارتقاى سلامت فردى و ويشخَيرى از بيمارىها، دانش مقلمهه

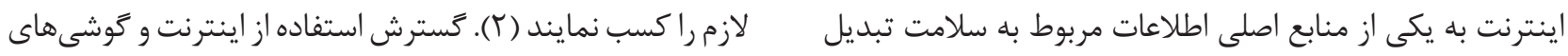

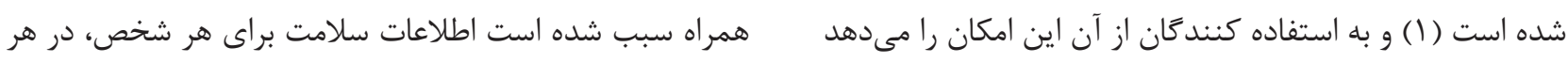


برخى از موارد با مرى و مير بالاتر همراه بوده و در واقع، بسيارى

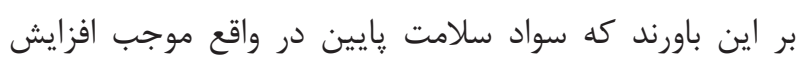

نابرابرىهاى سلامت خواهد شد (ب ا ).

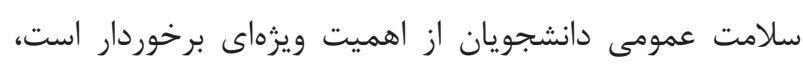

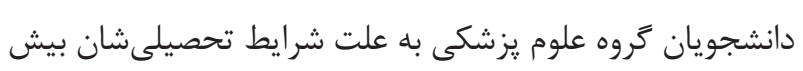

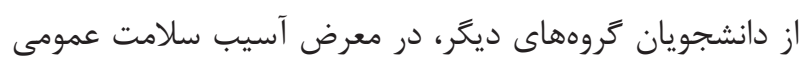

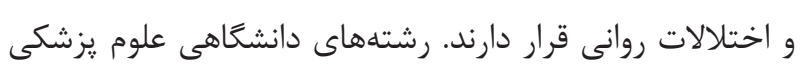

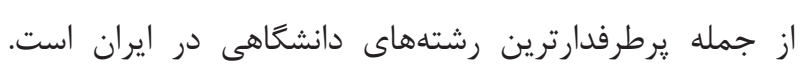

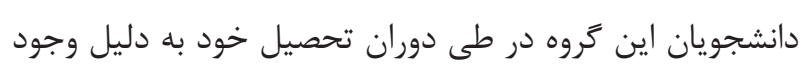

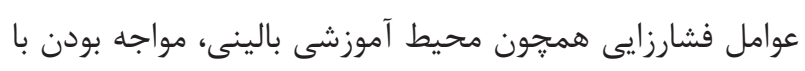

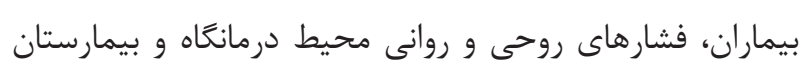

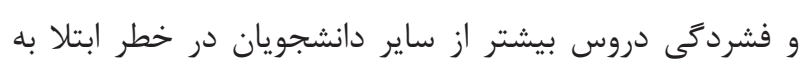

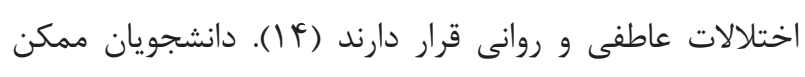

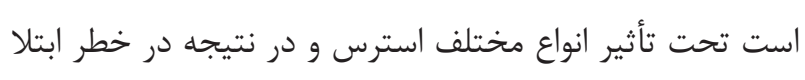

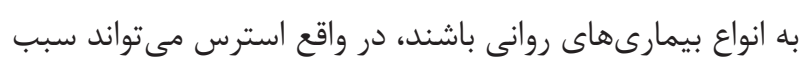

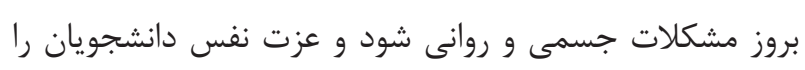

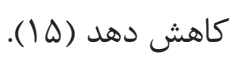

مطالعاتى در اين خصوص در دنيا انجام گرفته است. مطالعه

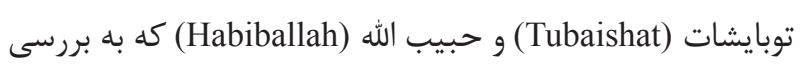
سطح سواد سلامت الكترونيك دانشجويان يرستارى در اردن بيش

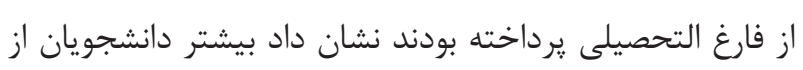

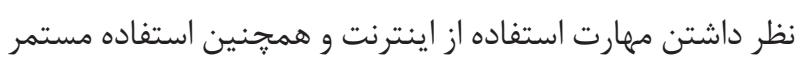

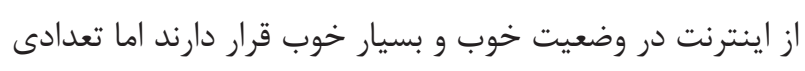
از دانشجويان نيز نيازمند افزايش مهارتهاى استفاده از اينترنت

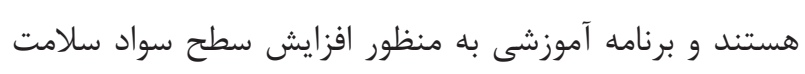

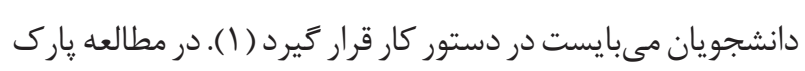

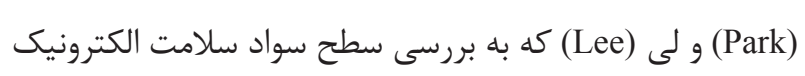

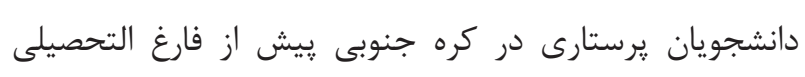

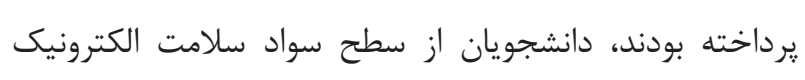

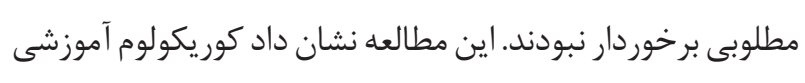

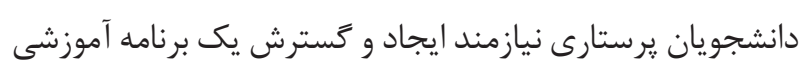
به منظور ارتقاى سطح سواد سلامت الكترونيك اين دانشجويان

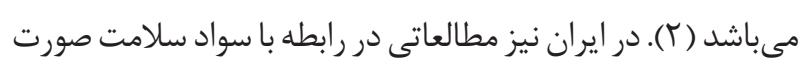

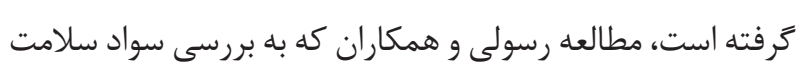

مكان و زمانى در دسترس باشد (ץ). سواد سلامت يك مسئله

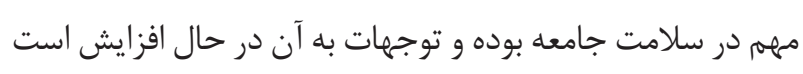

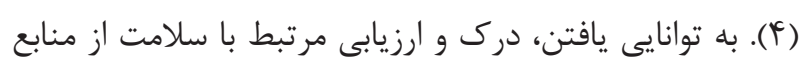

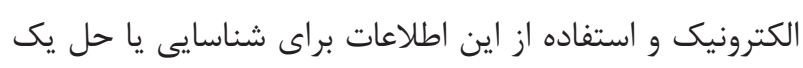

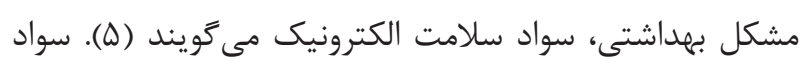

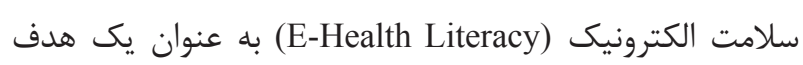
عمومى سلامت در قرن حاضر در نظر ترفته شده است (ع) جرا

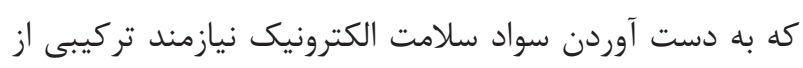
بهداشت، اطلاعات، دانش، رسانه، رايانه و سواد استفاده از اينترنت

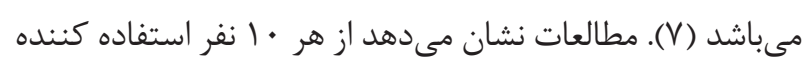

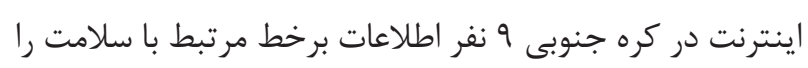
جستجو كردهاند (Y) باوجود مزاياى فراوانى كه استفاده از اينترنت

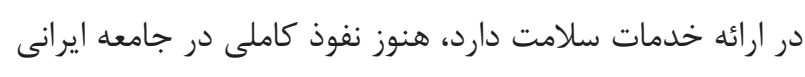

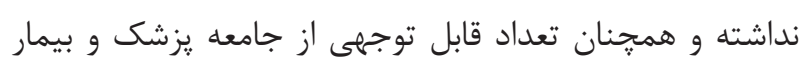

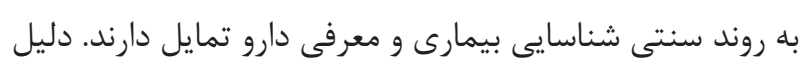

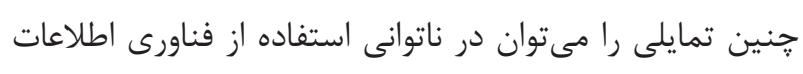
در راستاى حفظ سلامت دانست كه مستلزم توانايى خواندن،

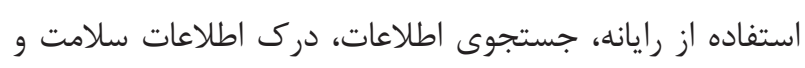
كاربرد آن است (^). سلامت عمومى يك موضوع جند بعدى مىباشد كه ابعاد آن بر يكديخر تأثير خذار بوده و تحت تأثير يكديخر قرار مى مَيرند (9).

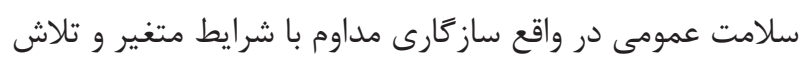

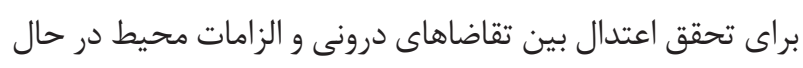
تغيير است، بنابر اين افر ادى كه بتوانند با محيط خود ساز كار ترد بردند

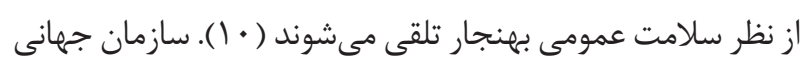

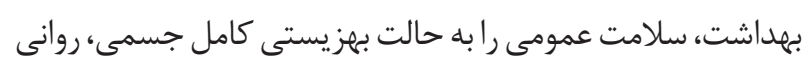
و اجتماعى و نه فقط فقدان بيمارى يا ناتوانى تعريف مى كند كه بين بندين

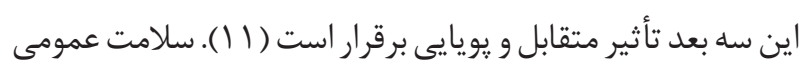
وضعيت جسمى، روانى و اجتماعى افراد است كه ارزيابى آن در

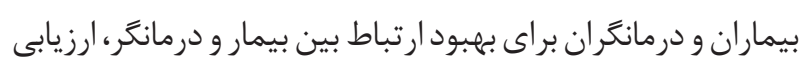

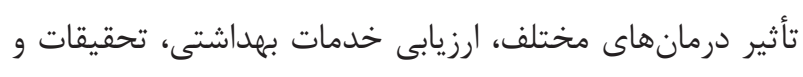
سياست كذارى لازم مىباشد (r I ). مطالعات نشان مى دهد سطح سواد سلامت پايين با نتايج نامطلوب

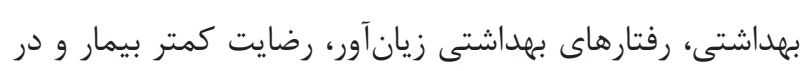


با سطح سواد سلامت الكترونيك بيماران داشته و استراتزىهاى بهبود رفتارهاى ارتقاء دهنده سلامت در بيماران مبتلا به ديابت

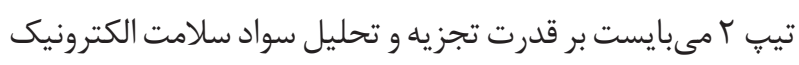

و عمق بخشيدن به اطلاعات آنلاين آنها استوار باشد (· (r).

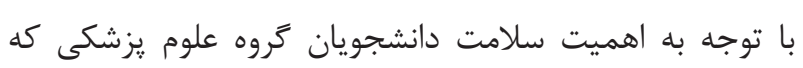

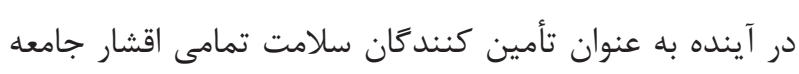

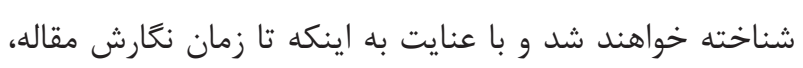

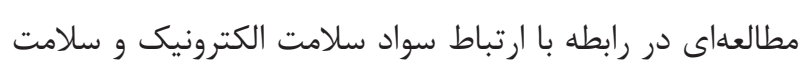

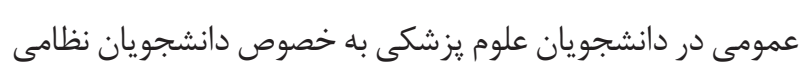

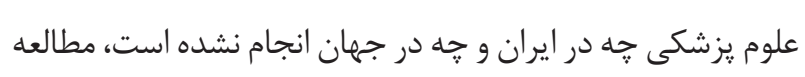

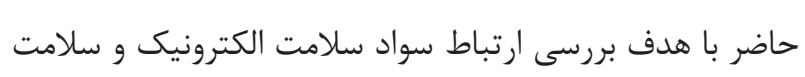

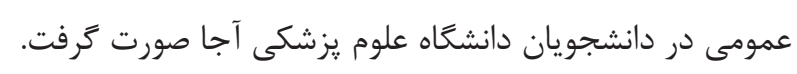

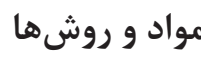

مطالعه حاضر يك مطالعه توصيفى-تحليلى و مقطعى در سال

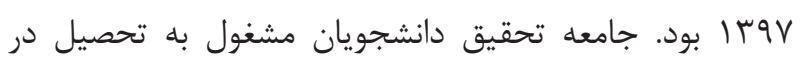

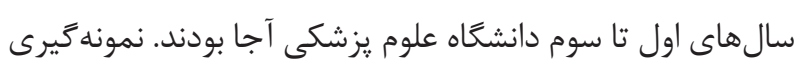
به روش آسان انجام شد و حجم نمونه از فرمول كوكران محاسبه $\mathrm{n}=\frac{\frac{\mathrm{z}^{r} \mathrm{pq}}{\mathrm{d}^{r}}}{1+\frac{1}{\mathrm{n}}\left[\frac{\mathrm{z}^{r} \mathrm{pq}}{\mathrm{d}^{r}}-1\right]}$

$z=1 / 94, P=\cdot / \Delta, q=1-p, d=\cdot / \cdot \Delta, N=q r$.

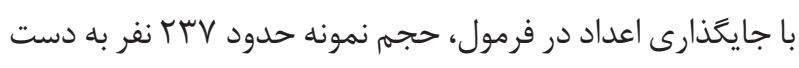

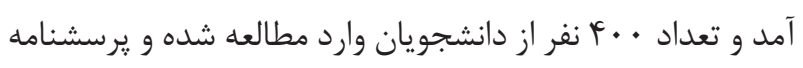

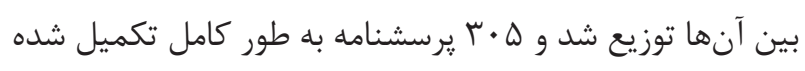

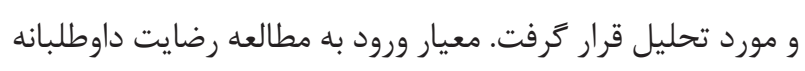
و آكاهانه و اشتغال به تحصيل در سه سال اول تحصيلى دانشگاه علوم يزشكى آجا بوده و معيار خروج عدم همكارى در مطالعه و تكميل ناقص برسشنامهها بود.

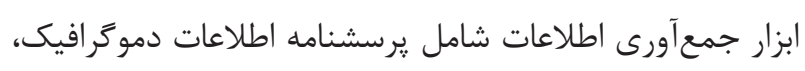
يرسشنامه سواد سلامت الكترونيك و يرسشنامه سلامت عمومى بود. يرسشنامه اطلاعات دمو گر افيك شامل رشته تحصيلى، جنس،

الكترونيك و عوامل بيش بينى كننده آن در ميان بيماران مراجعه

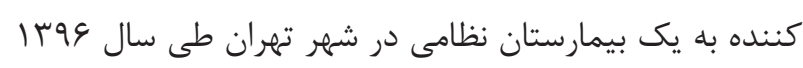

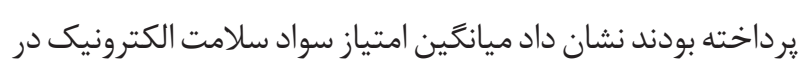

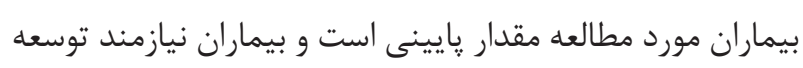

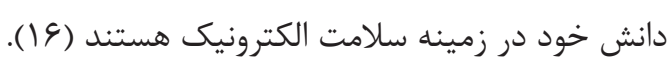
در رابطه با سلامت عمومى نيز مطالعاتى انجام كرفته است، مطالعه زينه

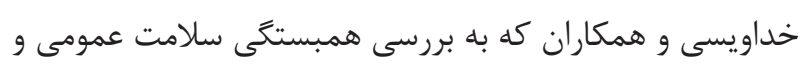

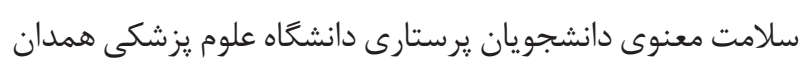

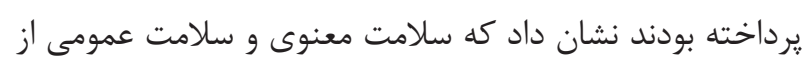

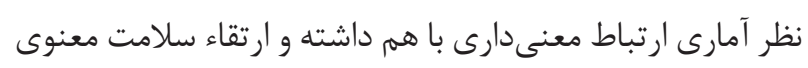

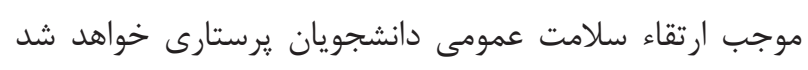

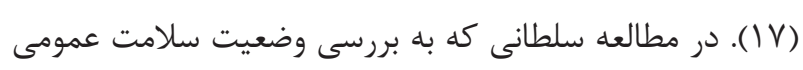

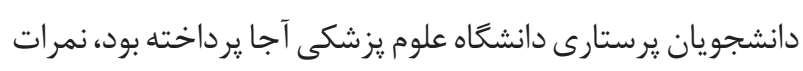
سلامت عمومى دانشجويان حاكى از وضعيت مناسب دانشجويان

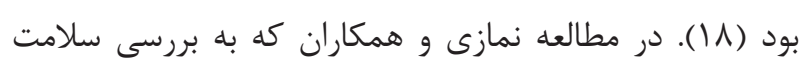

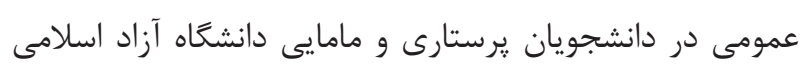

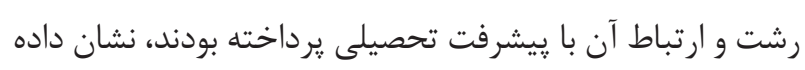

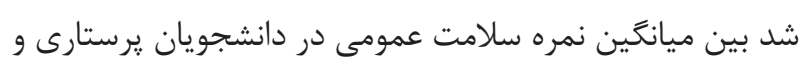
مامايى، اختلاف آمارى معنى دارى وجود دارد، در مطالعه مذكور

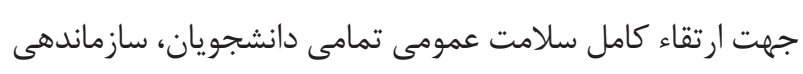
برنامههاى آموزشى و فعال نمودن مراكز مشاوره در سطح دانشكاه هـا

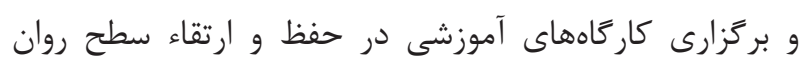

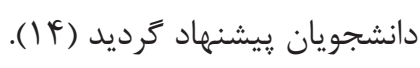
تا زمان نغارش مقاله مطالعات محدودى در زمينه ارتباط بين سواد بند سلامت و سلامت عمومى صورت گرفته بود. در مطالعه افتيميو

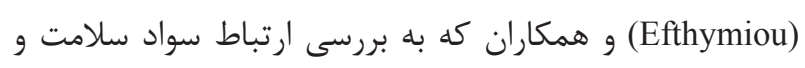

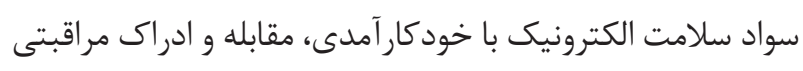

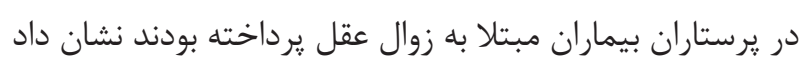

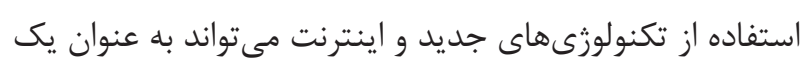
تسهيل كيم (Kim) و همكاران كه به بررسى ارتباط سطح سواد سلامت فرت

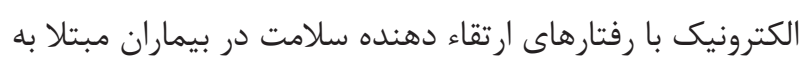

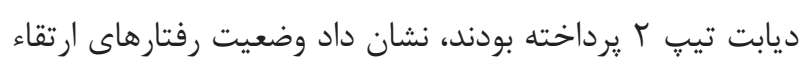

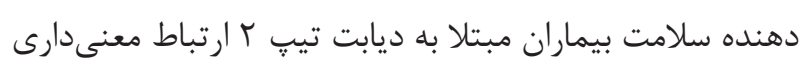


همجنين در اين يزوهش براى مطالعه روايى برسشنامه سلامت

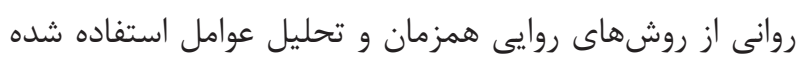

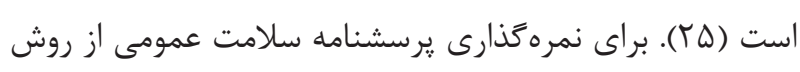

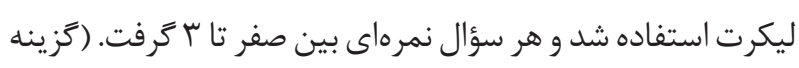

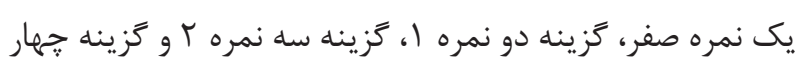

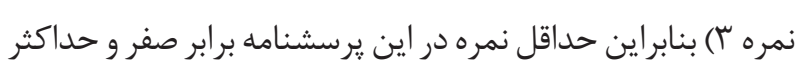

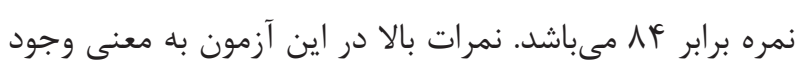

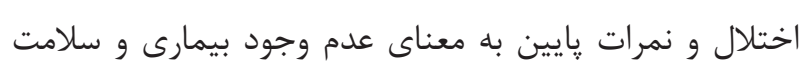

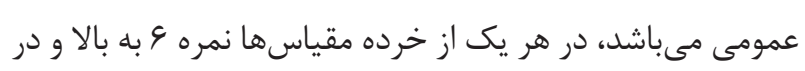

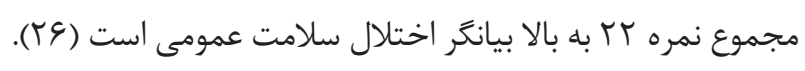
براى توصيف دادهها از ميانخين و انحراف معيار براى بررسى نرمال بودن دادهها از آزمون كولموكروف-اسميرنوف استفاده شد. جهت

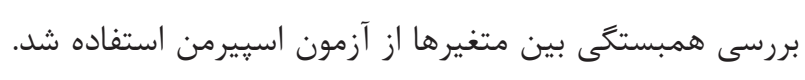

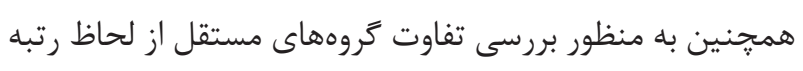
بندى از آزمونهاى كروسكال واليس و من ويتنى استفاده شد.

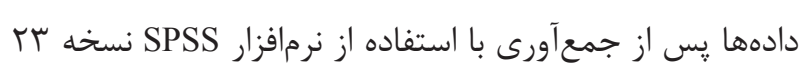

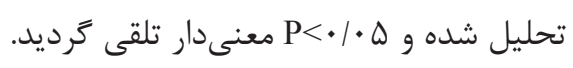

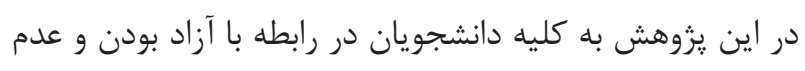
اجبار براى شركت در يزوهش اطمينان داده شد، كليه اطلاعات دانشجويان به صورت محرمانه حفظ و بدون نام منتشر شد. انجام

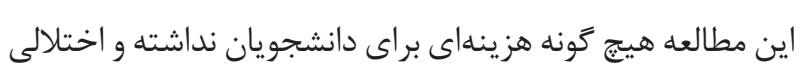

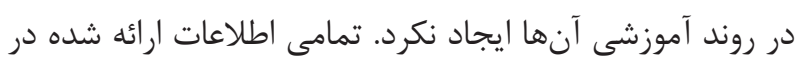

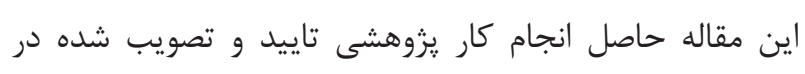

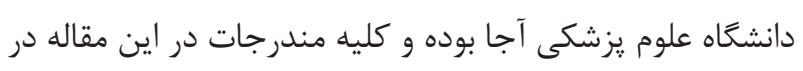

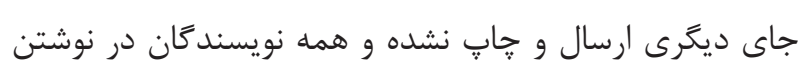
مقاله مشاركت داشتهاند. اين مطالعه در كميته اخلاق دانشكاه

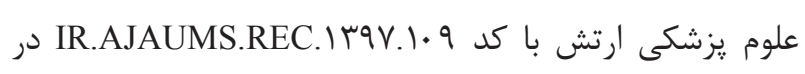

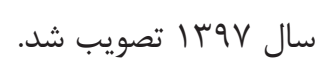

يافتهها

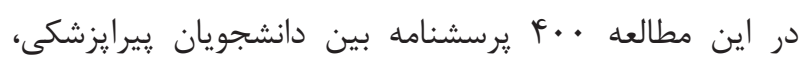

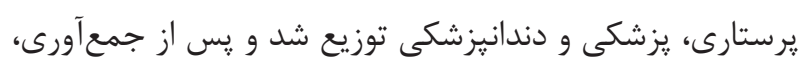

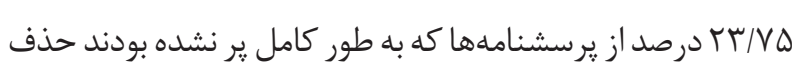

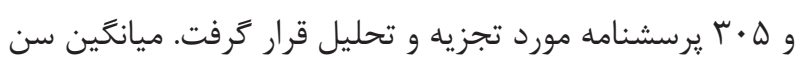

سن، مقطع تحصيلى و سال مشغول به تحصيل بود.

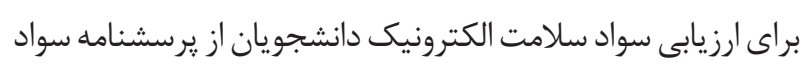

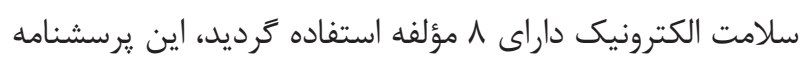
توسط نورمن (Norman) و همكاران طراحى كرديده است (ه).

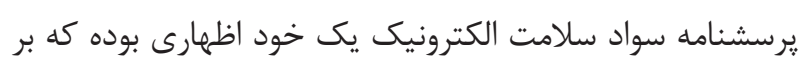

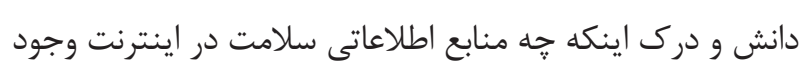

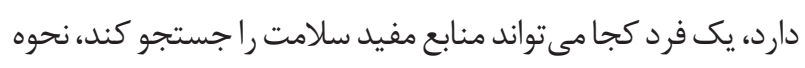

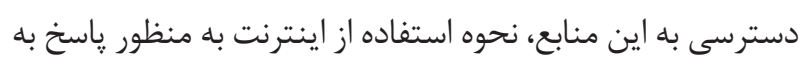

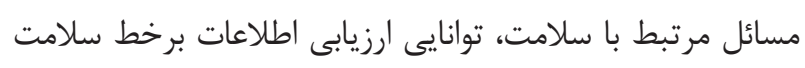
و تشخيص منابع بى كيفيت از منابع با كيفيت در اينترنت، تمركز

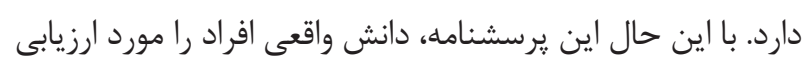

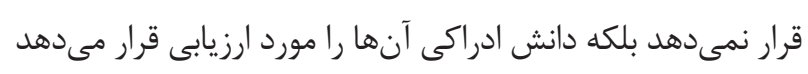

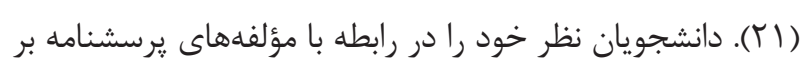

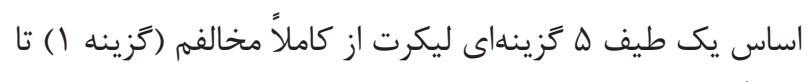

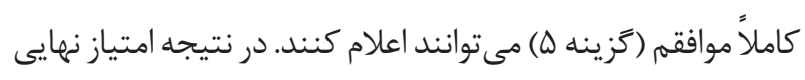

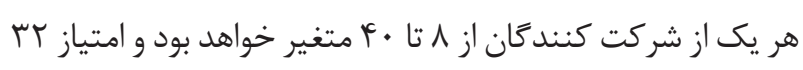

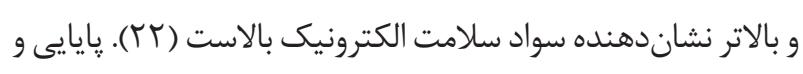

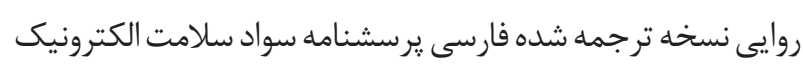
توسط بزم و همكاران بررسى شده است، آنها بار عاملى كويهها

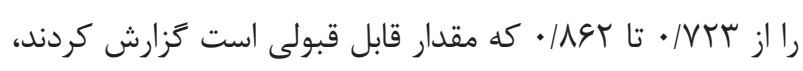

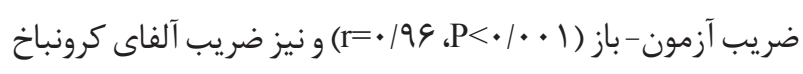

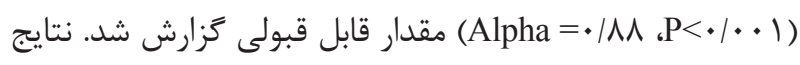
حاصل از اين مطالعه نشان داد نسخه ترجمه شده يرسشنامه هم

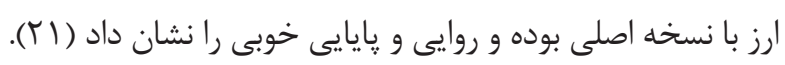

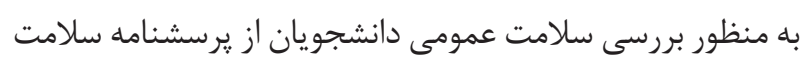

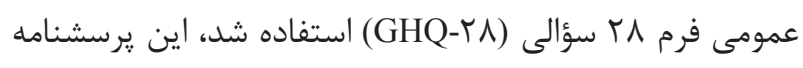
توسط كلدبرى (Goldberg) و همكاران طراحى شد. اين فرم

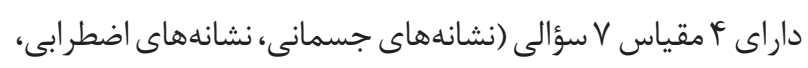

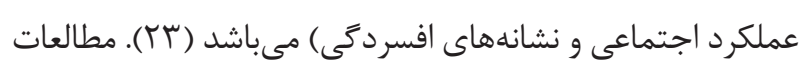

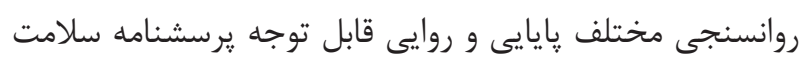

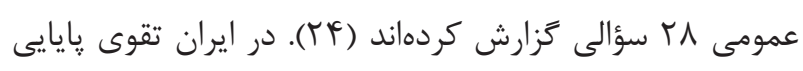

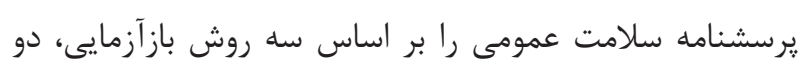

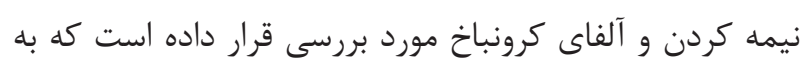

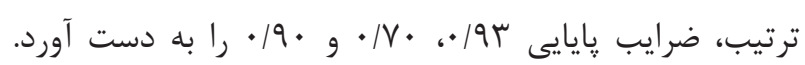


دموكر افيكى رشته تحصيلى، جنس و مقطع تحصيلى مشاهده نشد

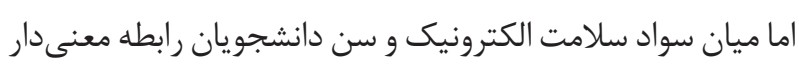

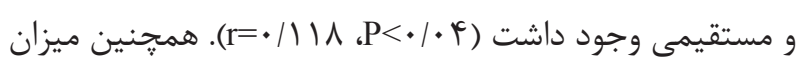

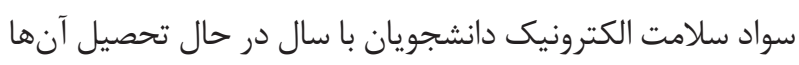

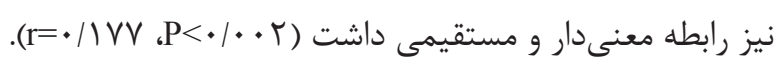

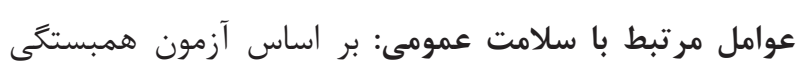

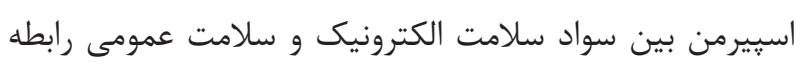

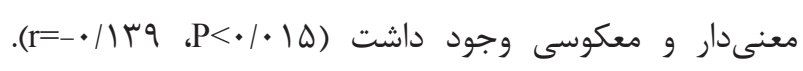
همجنين سلامت عمومى دانشجويان با رشته تحصيلى آنها

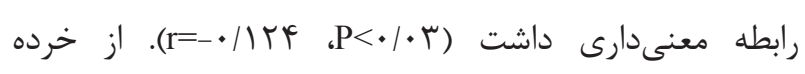

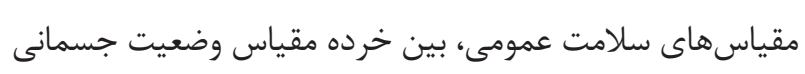

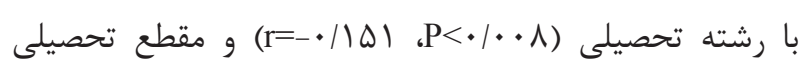

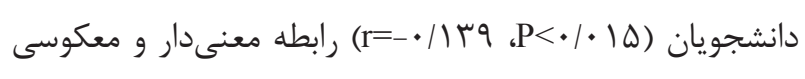
وجود داشت. بين خرده مقياس اضطراب و بىخوابى نيز با رشته

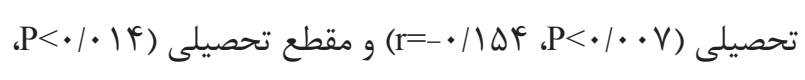

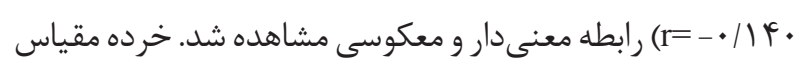

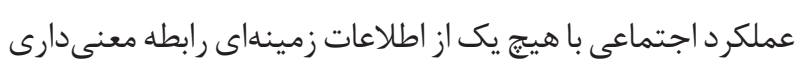

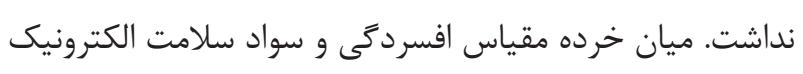

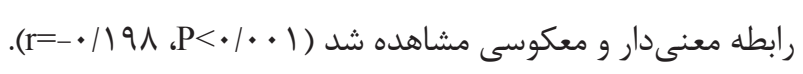

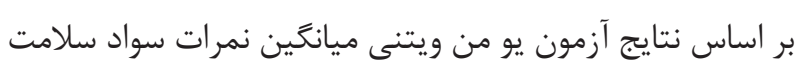

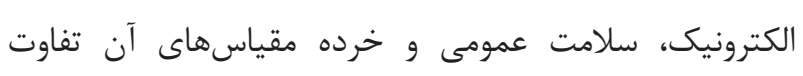
معنىدارى در دانشجويان دختر و يسر نداشت، نتايج آزمون

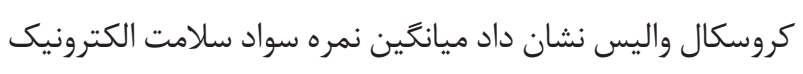
در سال مشغول به تحصيل دانشجويان تفاوت معنى دارى دارد (P< و نمره دانشجويان سال سوم نسبت به سال هاى يايينتر

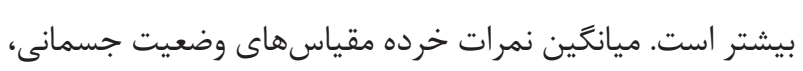

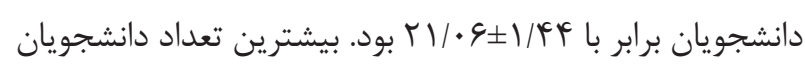

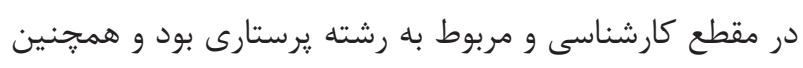

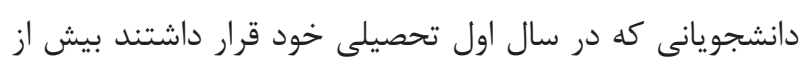
دانشجويان سال دوم و سال سوم بودند. (جدول ( )

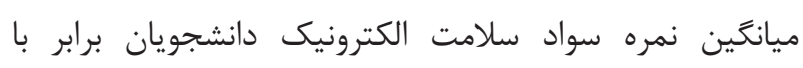
• با TV/TY

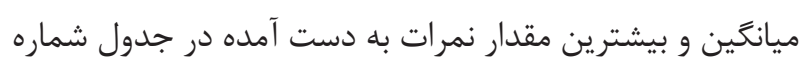
r ذان

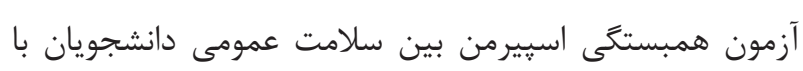

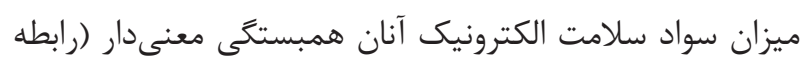

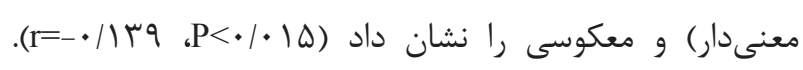

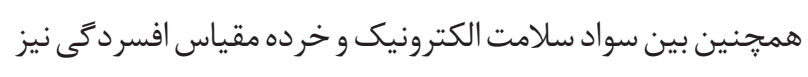

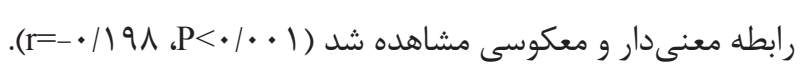

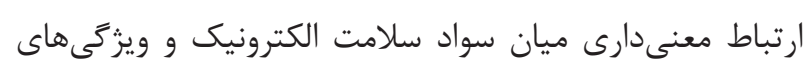
جدول ا- فراوانى دانشجويان بر اساس مقطع، رشته تحصيلى و سال در حال

\begin{tabular}{|c|c|c|c|}
\hline درصد & تعداد & 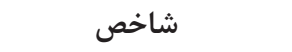 & متغير \\
\hline$\Delta / 9$ & 11 & كاردانى & \multirow{3}{*}{ مقطع تحصيلى } \\
\hline $99 / 0$ & $r \cdot r$ & كارشناسى & \\
\hline$r V / q$ & $\Lambda \Delta$ & دكترى & \\
\hline$\Delta \cdot 1 \Lambda$ & $1 \Delta \Delta$ & يرستارى & \multirow{3}{*}{ رشته تحصيلى } \\
\hline TV/A & $\Lambda \Delta$ & يزشكى و دندان يزشكى & \\
\hline$r M / 4$ & 90 & بيرإيزشىى & \\
\hline$r \cdot / V$ & IKF & سال اول & \multirow{3}{*}{ سال در حال تحصيل } \\
\hline$r 9 / 1$ & 91 & سال دوم & \\
\hline$r q / \Delta$ & 9. & سال سوم & \\
\hline
\end{tabular}

جدول r - كمترين مقدار ، ميانغين و بيشترين مقدار نمرات دانشجويان

\begin{tabular}{|c|c|c|c|c|}
\hline & بيشتر ين مقدار & ميانغين & كمتر ين مقدار & \\
\hline & r. & $r N / 1 Q \pm \Delta / q$. & $\Lambda$ & سواد سلامت الكترونيك \\
\hline & $\Delta F$ & $T V / T Y \pm 19 / 9 V$ & $\cdot$ & سلامت عمومى \\
\hline & rI & $9 / 99 \pm F / 0$. & · & وضعيت جسمانى \\
\hline & rI & $\varepsilon / 9 \Gamma \pm \Delta / \mu$. & · & اضطراب و بى خوابى \\
\hline & ri & $\Lambda / r \omega \pm r / \uparrow \Delta$ & . & عملكرد اجتماعى \\
\hline שחז & $r 1$ & $\Delta / V \cdot \pm Y / q Q$ & $\cdot$ & افسردىى \\
\hline
\end{tabular}


و سلامت عمومى دانشجويان دانشعاه علوم يزشكى آجا انجام

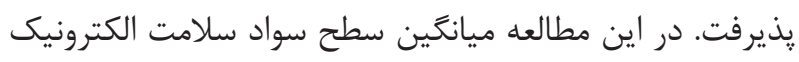

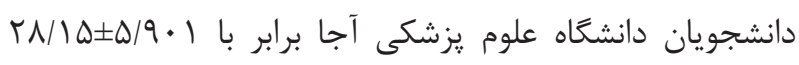

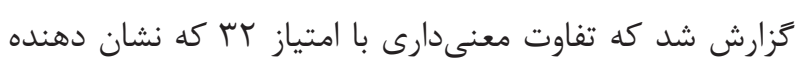

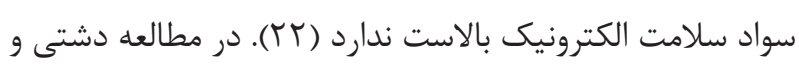
همكاران (TV) كه به بررسى سواد سلامت الكترونيك دانشجويان

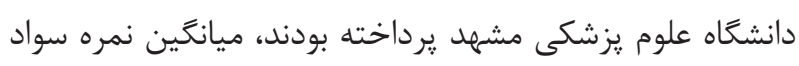

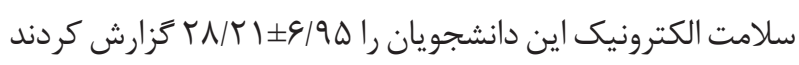

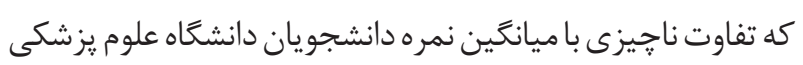

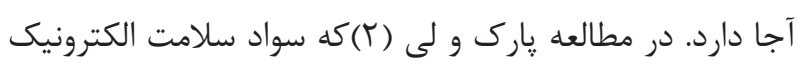

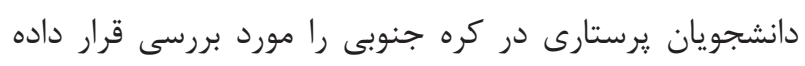

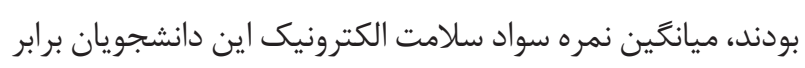

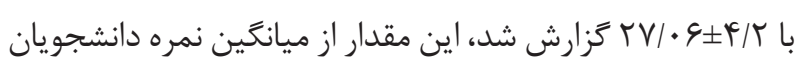
علوم يزشكى آجا يايينتر بوده اما تفاوت كمى با يكديكر دارند.

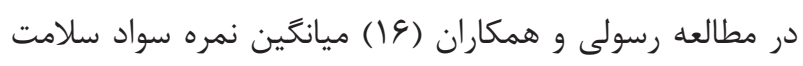

اضطراب و بى خوابى و عملكرد اجتماعى در رشتههاى مختلف

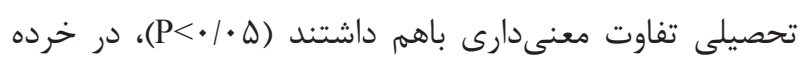

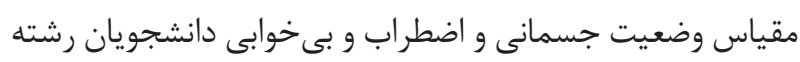

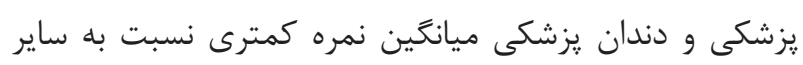

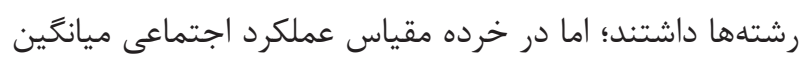

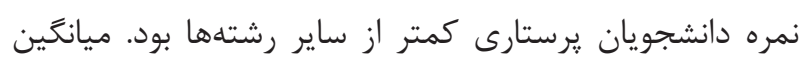
نمره خرده مقياس وضعيت جسمانى در سال تحصيلى نيز تفاوت

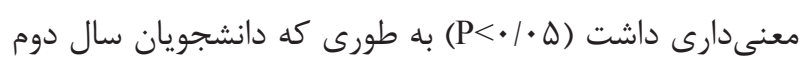

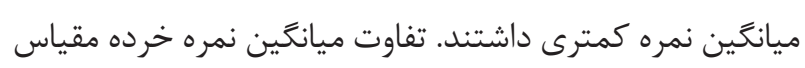

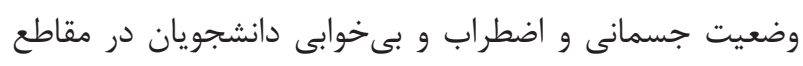

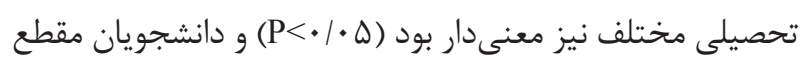

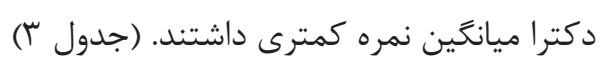

بحث و نتيجه اين مطالعه با هدف بررسى ارتباط بين سواد سلامت الكترونيك

جدول بـ- ميانگين و نمرات سواد سلامت الكترونيك و سلامت عمومى دانشجويان به تفكيك مشخصات زمينهاى

\begin{tabular}{|c|c|c|c|c|c|c|c|c|c|c|c|c|}
\hline \multicolumn{3}{|c|}{ مقطع تحصيلى } & \multicolumn{3}{|c|}{ سال مشغول به تحصيل } & \multicolumn{3}{|c|}{ رشته تحصيلى } & \multicolumn{2}{|c|}{ جنس } & & \\
\hline دكترى & كارشناسى & كاردانى & سوم & دوم & اول & يزشكى & يرستارى & رِيرايزشكى & زن & مرد & & \\
\hline$r q / 1 r$ & TV/VG & $r V / q Y$ & $r q / r r$ & rN/AV & tG|AT & $r q / 4 r$ & TV/TA & rA/G. & $r V / F F$ & rN/FA & ميانگين & \multirow{3}{*}{ سواد سلامت } \\
\hline$\Delta / V \Delta$ & $91 \cdots$ & $\Delta / \cdot \wedge$ & $9 / 1 Y^{\mathrm{F}}$ & $\Delta / 9$. & $\Delta / V T$ & $\Delta / \Delta V$ & $\varepsilon / \mu \cdot$ & $\Delta / \cdot 9$ & $\Delta / V)$ & $\Delta / 9 \vee$ & انحراف معيار & \\
\hline \multicolumn{3}{|c|}{$\cdot 110$} & \multicolumn{3}{|c|}{$\cdot / \cdot \cdot V^{*}$} & \multicolumn{3}{|c|}{$\cdot 1 \cdot 1$} & \multicolumn{2}{|c|}{$\cdot 110$} & $\mathrm{p}$ & \\
\hline $0 / 91$ & $V / T)$ & $\wedge / \Lambda \Lambda$ & $r q / 1 r$ & $r F / \cdot \Delta$ & TN/T. & $r r / q$ & re/9 & $r T / Y^{c}$ & $r V / P Q$ & $r V / I T$ & ميانگين & سلامت عمومى \\
\hline$\Gamma / \Lambda \mid$ & $4|9|$ & $\Delta / 9 \bar{C}$ & $19 / 11$ & $\mid F / 1 r$ & $\mid N / F F$ & $I T / V \cdot$ & $19 / 49$ & $r \cdot / r$. & $19 / 0 T$ & $19 / \mathrm{VV}$ & انحراف معيار & \\
\hline \multicolumn{2}{|c|}{$\cdot / 11$} & & & $\cdot 1 \cdot V$ & & & $\cdot 1 \cdot V$ & & $\cdot / V$ & $\wedge$ & $\mathrm{P}$ & \\
\hline $0 / 9 \Lambda$ & $V / T)$ & $\Lambda / \Lambda \Lambda$ & $V / \Delta V$ & $91 \cdot r$ & $V / T \cdot$ & $0 / 9)$ & $V / \cdot \mathrm{F}^{2}$ & $N / 1 T$ & $V / 4 \varphi$ & G/VT & ميانگين & \multirow{3}{*}{ وضعيت جسمانى } \\
\hline \multirow[t]{2}{*}{ r/Al } & $|q| 9 \mid$ & $\Delta / 9 \varphi$ & $F / \cdot V$ & $F / \cdots$ & $\Delta / \cdot \varphi^{c}$ & $r / V \cdot$ & F/FT & $\Delta / \Gamma \Delta$ & $r / r \Lambda$ & $p / 09$ & انحراف معيار & \\
\hline & $\cdot 1 \cdot \Delta^{*}$ & & & $\cdot 1 \cdot r^{*}$ & & & $\cdot \mid \cdot \mu^{*}$ & & $\cdot 1 \cdot$ & - V & $\mathrm{P}$ & \\
\hline$\Delta / V^{c}$ & $\mathrm{~V} / 19$ & १/V८ & $V / F T$ & $91 \cdot 0$ & $V / T)$ & $\Delta / 9 \mu$ & 9/99 & $\Delta /{ }^{\top}$ & $V / T I$ & $9 / V 9$ & ميانگين & \multirow{3}{*}{ اضطراب و بى خوابى } \\
\hline \multirow[t]{2}{*}{$F / T \cdot$} & $\Delta / A T$ & 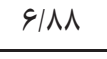 & r/ar & $F / V r$ & $\Delta / \wedge 9$ & $F / \cdot F$ & س & $9|\pi|$ & $\Delta / \uparrow \Delta$ & $\Delta / T F$ & انحراف معيار & \\
\hline & $\cdot / \cdot r^{*}$ & & & .119 & & & $\cdot / \cdot r^{*}$ & & $\cdot 10$ & $\Delta \wedge$ & $\mathrm{P}$ & \\
\hline$\Lambda / Q$. & N/IV & १/V८ & 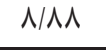 & V/V9 & $\Lambda / \Upsilon \Lambda$ & $\Lambda / M F$ & V/AD & $9 / \Delta \varphi$ & $N / \cdot 1$ & $N / D 1$ & ميانگين & \multirow{3}{*}{ عملكرد اجتماعى } \\
\hline \multirow[t]{2}{*}{$r / \cdot 1$} & T/QT & $F / F$ & $r / v q$ & $r / 4 \mid$ & r/VA & T/A $\left.\right|^{\mathrm{L}}$ & r/T^ & $F / \cdot \varphi^{c}$ & T/TQ & $\Delta / \Delta \Gamma$ & انحراف معيار & \\
\hline & $\cdot / \pi \Delta$ & & & $\cdot 111$ & & & $\cdot 1 \cdot 10^{*}$ & & $\cdot / 4$ & tr & $\mathrm{P}$ & \\
\hline r/AV & $\Delta / \Gamma \wedge$ & $\Delta / Y^{c} \mid$ & $Q / Y F$ & F/1 & $\Delta / \mu r$ & $r / V \Delta$ & $\Delta / 11$ & $9 / 19$ & F/VG & $\Delta / \cdot \Delta$ & ميانگين & \multirow{3}{*}{ افسردگى } \\
\hline \multirow[t]{2}{*}{ F/fr } & $9 / 1 F$ & $\Delta / \Delta q$ & $\Delta / \bar{c}$. & $\Delta / F V$ & $0 / 9 \pi$ & f/Tr & $\Delta / 9 \Delta$ & G/FT & $0 / 9$. & D/9T & انحراف معيار & \\
\hline & • & & & $\cdot / r \cdot$ & & & $\cdot / \pi$ & & $\cdot 10$ & & $\mathrm{P}$ & \\
\hline
\end{tabular}


دانشجويانى كه در سال تحصيلى سوم خود قرار داشتند داراى

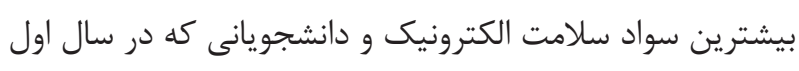

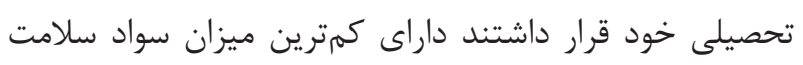

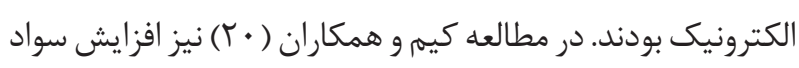

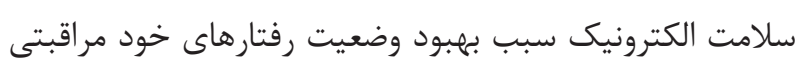
در بيماران مبتلا به ديابت تيب ا م مىشد.

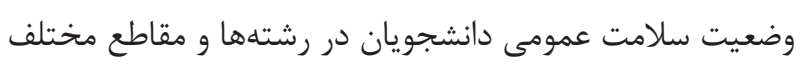

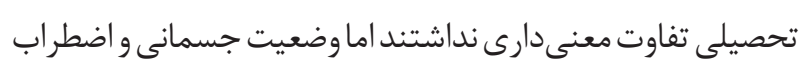
و بى خوابى دانشجويان رشته يزشكى و دندانيزشكى كه در در مقطع

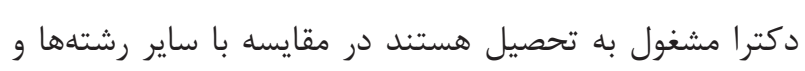

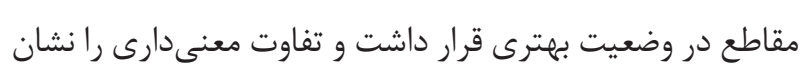
مى دهد، اين تفاوت مى تواند ناشى از تحرك بيشتر اين دانشجويان

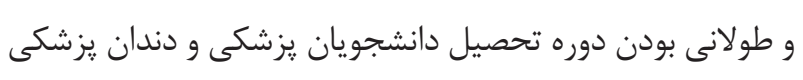

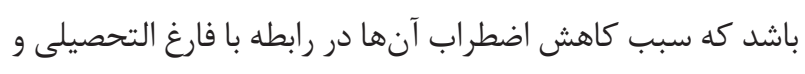

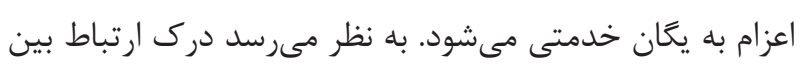

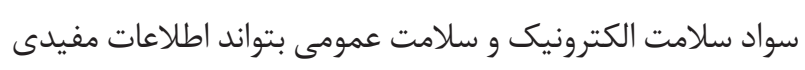

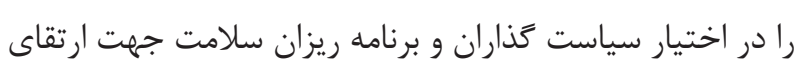
سلامت عمومى و ارتقاى سواد سلامت دانشجويان قرار دهد. از جمله محدوديتهاى يزوهش، مطالعه بر روى دانشجويان دانشعاه

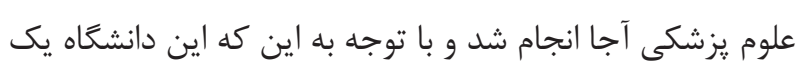

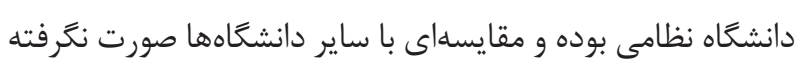

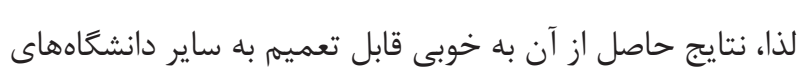
علوم يزشكى كشور نمىباشد.

\section{تشكر و قدردانى}

بدين وسيله از تمامى دانشجويانى كه در اين طرح مشاركت

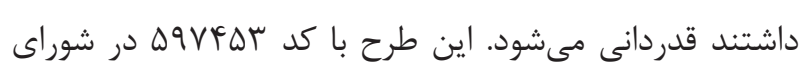

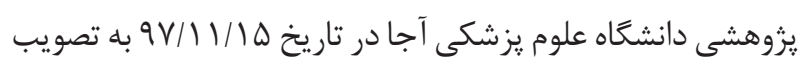
رسيده است.

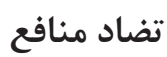

در اين مطالعه هيج كَونه تضاد منافعى بين نويسندًان وجود ندارد.
الكترونيك بيماران مراجعه كننده به يك بيمارستان نظامى در

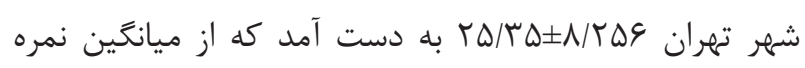

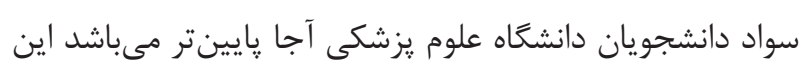

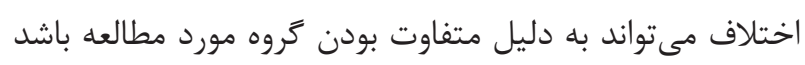
كه در مطالعه مورد مقايسه بيماران بودند.

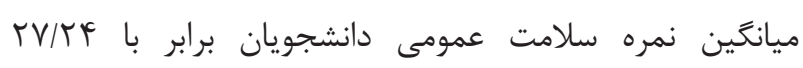

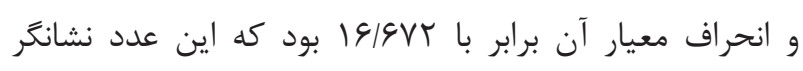

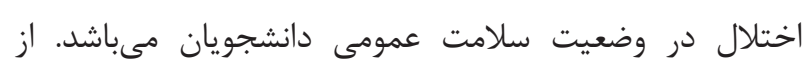

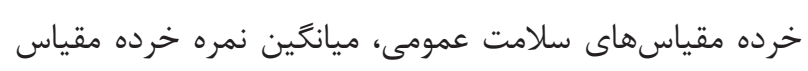

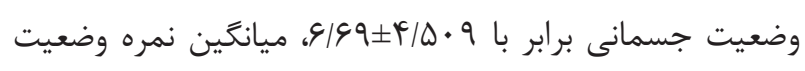

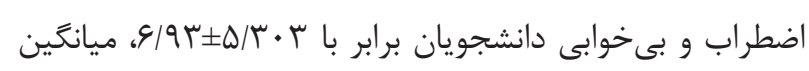

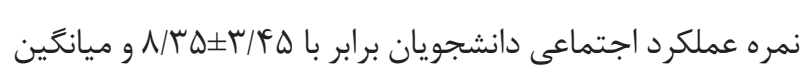

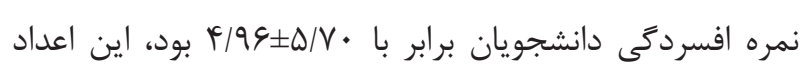
بيانكر وضعيت مناسب دانشجويان از لحاظ افسردگى و اختلال

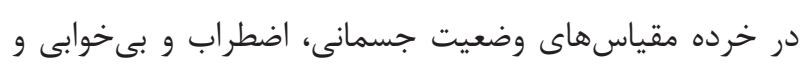

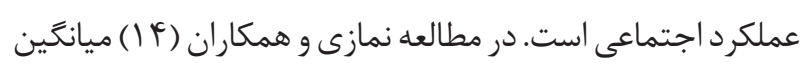
و انحراف معيار سلامت عمومى دانشجويان يرستارى و مامايى

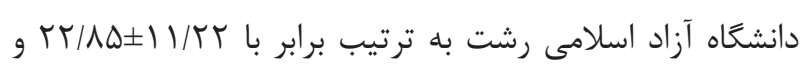

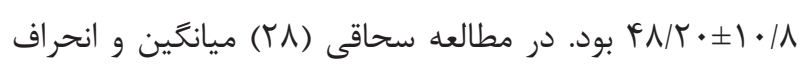

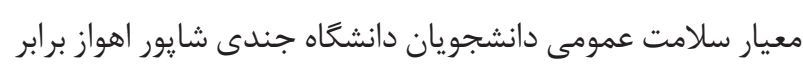

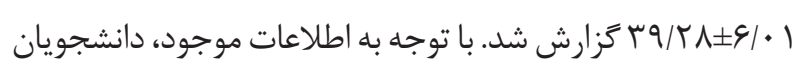

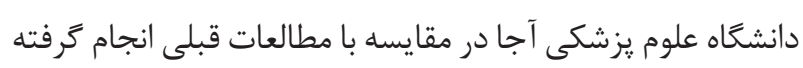
در دانشخاههاى مختلف، وضعيت سلامت عمومى بهترى دارند، اين تفاوت با توجه به وجود قوانين نظامى در دانشخاه اعم از ساعات بيدارى و خاموشى مشخص، وجود دورههاى نظامى با تحرى بالا و رزيم غذايى كم كالرى قابل توجيه است. مطالعه حاضر نشان داد، هرقدر سواد سلامت الكترونيك دانشجويان

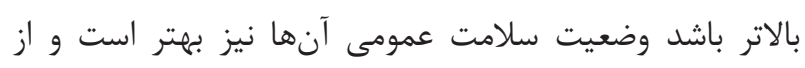

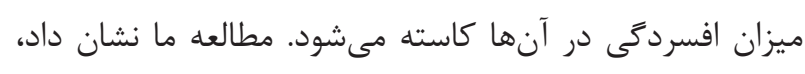

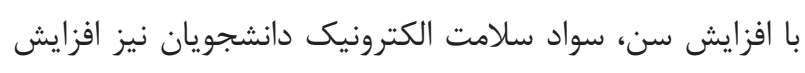

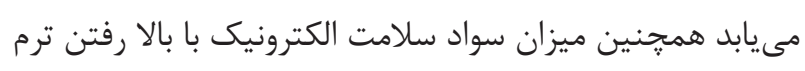

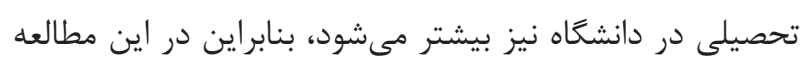




\section{References}

1- Tubaishat A, Habiballah L. eHealth literacy among undergraduate nursing students. Nurse Educ Today. 2016;42:47-52. http:// dx.doi.org/10.1016/j.nedt.2016.04.003 www.ncbi.nlm.nih.gov/ pubmed/27237352

2- Park H, Lee E. Self-reported eHealth literacy among undergraduate nursing students in South Korea: a pilot study. Nurse Educ Today. 2015;35(2):408-13. http://dx.doi.org/10.1016/j.nedt.2014.10.022 www.ncbi.nlm.nih.gov/pubmed/25466791

3- Robb M, Shellenbarger T. Influential factors and perceptions of eHealth literacy among undergraduate college students. On-Line Journal of Nursing Informatics. 2014;18(3).

4- Eden K, Mann M, Miller G, Abraham S. Health Literacy and Use of Preventative Care of Female Undergraduate Nursing vs. NonNursing Students. International Journal of Studies in Nursing. 2017;3(1). http://dx.doi.org/10.20849/ijsn.v3i1.230

5- Norman CD, Skinner HA. eHEALS: The eHealth Literacy Scale. J Med Internet Res. 2006;8(4):e27. http://dx.doi.org/10.2196/ jmir.8.4.e27 www.ncbi.nlm.nih.gov/pubmed/17213046

6- Rootman I. Literacy and health in Canada: is it really a problem? Can J Public Health. 2003;94(6):405-7, 12. www.ncbi.nlm.nih. gov/pubmed/14700236

7- Chan CV, Kaufman DR. A framework for characterizing eHealth literacy demands and barriers. J Med Internet Res. 2011;13(4):e94. http://dx.doi.org/10.2196/jmir.1750 Www.ncbi.nlm.nih.gov/ pubmed/22094891

8- Ghazimirsaeed S, Ghaemizade M. E-Health Literacy among Postgraduate Students in Tehran University of Medical Sciences, Iran, during 2015-2016. Health Inf Manage 2018;14(6):243-8.

9- Hosseini VJ. Community health nursing 1st ed. Tehran: Jameeh Negar; 2008.

10- Amini R, Soleymani F, Mohammadi N, Tapak L. Relationship between Communication Skills and General Health in Nursing Students of Hamadan University of Medical Sciences. J Educat \& Community Health. 2018;5(2):36-44. http://dx.doi.org/10.21859/ jech.5.2.36

11- Chung PJ, Chiou CJ, Chou FH. Relationships between health status, depression and cognitive functions of institutionalized male veterans. Arch Gerontol Geriatr. 2009;49(2):215-9. http:// dx.doi.org/10.1016/j.archger.2008.08.002 www.ncbi.nlm.nih.gov/ pubmed/19058864

12- Sinha N, Singh B, Chhabra KG, Patil S. Comparison of oral health status between children with cerebral palsy and normal children in India: A case-control study. J Indian Soc Periodontol. 2015;19(1):78-82. http://dx.doi.org/10.4103/0972-124X.145800 www.ncbi.nlm.nih.gov/pubmed/25810598

13- Farin E, Ullrich A, Nagl M. Health education literacy in patients with chronic musculoskeletal diseases: development of a new questionnaire and sociodemographic predictors. Health Educ Res. 2013;28(6):1080-91. http://dx.doi.org/10.1093/her/cyt095 www. ncbi.nlm.nih.gov/pubmed/24113084
14- Namazi A. General health in nursing and midwifery students and its relationship with academic achievement. J Nursing Educat. 2015;4(3):11-8.

15- Thelwell RC, Lane AM, Weston NJV. Mood states, self-set goals, self-efficacy and performance in academic examinations. Personality and Individual Differences. 2007;42(3):573-83. http:// dx.doi.org/10.1016/j.paid.2006.07.024

16- Rasouli H, Abbasi Farajzadeh M, Tadayon A. Evaluation of e-Health Literacy and Its Predictor Factors among Patients Referred To a Military Hospital in Tehran, Iran, 2017. J Military Med. 2018;20(1):83-92.

17- Khodaveisi M, Baiat M, Amini R, Roshanaei G. The correlatlon of general and spiritual health of nursing students in hamedan University of medical sciences in 2016. Avicenna J Nurs \& Midwif Care 2017;25(3):26-33. http://dx.doi.org/10.21859/nmj-25034

18- Soltani N. General Health Status of Nursing Students in AJA University of Medical Sciences. Military Caring Sciences. 2016;2(4):191-6. http://dx.doi.org/10.18869/acadpub.mcs.2.4.191

19- Efthymiou A, Middleton N, Charalambous A, Papastavrou E. The Association of Health Literacy and Electronic Health Literacy With Self-Efficacy, Coping, and Caregiving Perceptions Among Carers of People With Dementia: Research Protocol for a Descriptive Correlational Study. JMIR Res Protoc. 2017;6(11):e221. http:// dx.doi.org/10.2196/resprot.8080 www.ncbi.nlm.nih.gov/ pubmed/29133284

20- Kim KA, Kim YJ, Choi M. Association of Electronic Health Literacy With Health-Promoting Behaviors in Patients With Type 2 Diabetes: A Cross-sectional Study. Comput Inform Nurs. 2018;36(9):43847. http://dx.doi.org/10.1097/CIN.0000000000000438 www.ncbi. nlm.nih.gov/pubmed/29742548

21- Bazm S, Mirzaei M, Fallahzadeh H, Bazm R. Validity and reliability of Iranian version of eHealth literacy scale. J Commun Health Res. 2016;5(2):121-30.

22- Park H, Cormier E, Gordon G, Baeg JH. Identifying Health Consumers' eHealth Literacy to Decrease Disparities in Accessing eHealth Information. Comput Inform Nurs. 2016;34(2):71-6; quiz 99. http://dx.doi.org/10.1097/CIN.0000000000000205 www.ncbi. nlm.nih.gov/pubmed/26657619

23- Sigfusdottir ID, Kristjansson AL, Allegrante JP. Health behaviour and academic achievement in Icelandic school children. Health Educ Res. 2007;22(1):70-80. http://dx.doi.org/10.1093/her/cyl044 www.ncbi.nlm.nih.gov/pubmed/16766605

24- Datar A, Sturm R, Magnabosco JL. Childhood overweight and academic performance: national study of kindergartners and firstgraders. Obes Res. 2004;12(1):58-68. http://dx.doi.org/10.1038/ oby.2004.9 www.ncbi.nlm.nih.gov/pubmed/14742843

25- Taghavi S. Validity and reliability of the general health questionnaire (ghq-28) in college students of shiraz university. J psychology. 2002;5(4):381-98.

26- Goldberg DP, Hillier VF. A scaled version of the General Health 
Questionnaire. Psychol Med. 1979;9(1):139-45. http://dx.doi. org/10.1017/s0033291700021644 www.ncbi.nlm.nih.gov/ pubmed/424481

27- Dashti S, Peyman N, Tajfard M, Esmaeeli H. E-Health literacy of medical and health sciences university students in Mashhad, Iran in 2016: a pilot study. Electron Physician. 2017;9(3):3966-73. http://dx.doi.org/10.19082/3966 www.ncbi.nlm.nih.gov/ 